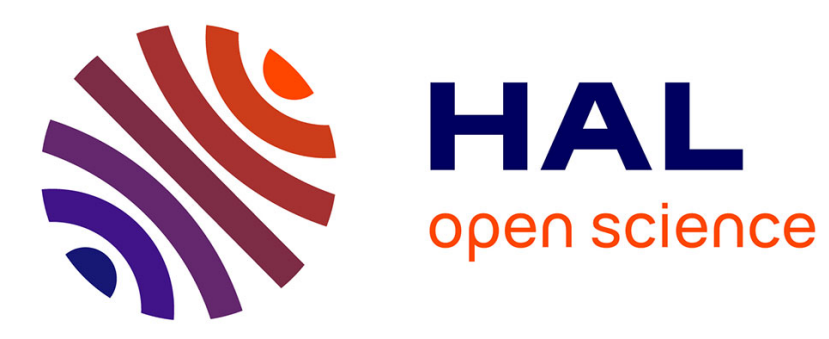

\title{
Speed of Sound Measurements and the Methane Abundance in Titan's Atmosphere
}

\author{
A. Hagermann, P.D. Rosenberg, M.C. Towner, J.R.C. Garry, H. Svedhem, \\ M.R. Leese, B. Hathi, R.D. Lorenz, J.C. Zarnecki
}

\section{- To cite this version:}

A. Hagermann, P.D. Rosenberg, M.C. Towner, J.R.C. Garry, H. Svedhem, et al.. Speed of Sound Measurements and the Methane Abundance in Titan's Atmosphere. Icarus, 2007, 189 (2), pp.538. 10.1016/j.icarus.2007.02.004 . hal-00499070

\section{HAL Id: hal-00499070 https://hal.science/hal-00499070}

Submitted on 9 Jul 2010

HAL is a multi-disciplinary open access archive for the deposit and dissemination of scientific research documents, whether they are published or not. The documents may come from teaching and research institutions in France or abroad, or from public or private research centers.
L'archive ouverte pluridisciplinaire HAL, est destinée au dépôt et à la diffusion de documents scientifiques de niveau recherche, publiés ou non, émanant des établissements d'enseignement et de recherche français ou étrangers, des laboratoires publics ou privés. 


\section{Accepted Manuscript}

Speed of Sound Measurements and the Methane Abundance in Titan's Atmosphere

A. Hagermann, P.D. Rosenberg, M.C. Towner, J.R.C. Garry,

H. Svedhem, M.R. Leese, B. Hathi, R.D. Lorenz, J.C. Zarnecki

PII: $\quad$ S0019-1035(07)00088-7

DOI: $\quad$ 10.1016/j.icarus.2007.02.004

Reference: $\quad$ YICAR 8195

To appear in: Icarus

Received date: 22 September 2006

Revised date: 7 February 2007

Accepted date: 8 February 2007

Please cite this article as: A. Hagermann, P.D. Rosenberg, M.C. Towner, J.R.C. Garry, H. Svedhem, M.R. Leese, B. Hathi, R.D. Lorenz, J.C. Zarnecki, Speed of Sound Measurements and the Methane Abundance in Titan's Atmosphere, Icarus (2007), doi: 10.1016/j.icarus.2007.02.004

This is a PDF file of an unedited manuscript that has been accepted for publication. As a service to our customers we are providing this early version of the manuscript. The manuscript will undergo copyediting, typesetting, and review of the resulting proof before it is published in its final form. Please note that during the production process errors may be discovered which could affect the content, and all legal disclaimers that apply to the journal pertain. 


\section{Speed of Sound Measurements and the Methane}

\section{Abundance in Titan's Atmosphere}

A. Hagermann ${ }^{1}$, P.D. Rosenberg ${ }^{1}$, M.C. Towner ${ }^{1}$, J.R.C. Garry ${ }^{2}$, H. Svedhem ${ }^{3}$, M.R. Leese $^{1}$, B. Hathi ${ }^{1}$, R.D. Lorenz ${ }^{1,4,5}$, J.C. Zarnecki ${ }^{1}$

1) PSSRI, The Open University, Walton Hall, Milton Keynes, United Kingdom.

2) Astrobiology Group, Leiden Institute of Chemistry, Leiden University, Leiden, Netherlands.

3) ESA/ESTEC, Research and Scientific Support Department, Noordwijk, Netherlands.

4) Lunar and Planetary Laboratory, University of Arizona, Tucson AZ, USA.

5) now at Space Department, Johns Hopkins University Applied Physics Laboratory, Laurel, MD, USA

\# pages: 18

\# figures: 5

\# tables: - 
Running header: Speed of sound and methane on Titan

Correspondence address:

Dr Axel Hagermann

Planetary and Space Sciences Research Institute

The Open University

Walton Hall

Milton Keynes

MK7 6AA

United Kingdom

a.hagermann@open.ac.uk 


\section{Abstract}

Aboard the Huygens probe, which descended through Titan's atmosphere in January 2005, was the Surface Science Package (SSP), a set of 9 sensors, including a speedof-sound sensor. We present the first detailed description of the SSP speed of sound measurements and report constraints on the methane content in Titan's lower atmosphere based on these measurements. After a careful calibration and subsequent Bayesian analysis, our measurements yield a most likely methane fraction in Titan's lower atmosphere of approximately $2 \%$ at $10 \mathrm{~km}$, increasing to $3.5 \%$ at lower altitudes, based on a binary composition. Our data show that any large scale variation of methane within the lower $11 \mathrm{~km}$ of Titan's atmosphere is unlikely. Within experimental and theoretical uncertainties, our results are compatible with earlier estimates obtained from the GCMS experiment (Niemann et al., 2005).

Keywords: TITAN; ATMOSPHERES, COMPOSITION 


\section{Introduction}

On $14^{\text {th }}$ January 2005 the Huygens probe landed on the surface of Titan, a culmination of a 7-year transatlantic development effort, a 7.5 year cruise in space, and a 2.5 hour descent through Titan's hazy atmosphere. Included as part of the mission's science instrumentation was the Surface Science Package (SSP), a suite of instruments designed to measure specific properties of the atmosphere and surface of Titan; a full description of the operation of SSP can be found in Zarnecki et al. (2002, 2005). One SSP sensor, the Acoustic Properties Instrument-Velocimeter (API-V), aimed to measure the speed of sound in a hydrocarbon sea or lake, should Huygens land in a liquid. However, it was also able to make measurements in Titan's dense lower atmosphere. As Huygens landed on a solid surface only atmospheric measurements were made and these are presented here as the first measurements of the speed of sound made in a remote planetary atmosphere.

The speed of sound in a non-ideal gas, such as Titan's lower atmosphere, is dependent upon composition, temperature and pressure. Using the speed of sound, pressure, and temperature measurements from Huygens it is possible to estimate the methane content of Titan's atmosphere below $11 \mathrm{~km}$, given some simple initial constraints.

\section{Sensor and Measurements}

The instrument consisted of two sensor heads (API-V1 and API-V2) each containing a piezoelectric element able to act as both a transmitter and a receiver of ultrasound. The sensor heads were mounted opposite and facing each other across the SSP cavity allowing atmospheric gases to flow past them. The sensors were mounted at the 
opening of the cavity, but inside an electromagnetic shield, giving them the best possible exposure to Titan's atmosphere (see figure 1).

To make a measurement, a $1 \mathrm{MHz}$ sound wave of nominally $10 \mu$ s duration was transmitted between the sensors and the time of flight of this sound wave was measured. The sampling frequency was $4 \mathrm{MHz}$ giving a time resolution for the measurement of $0.25 \mu \mathrm{s}$. This process was repeated twice per second (once in each direction) potentially providing metre scale vertical resolution during the descent through Titan's atmosphere.

Experimentation with flight spare sensors has revealed that it takes a time $\mathrm{t}_{0}=3.71 \mu \mathrm{s}$ for the sound waves to propagate out of the transmitting sensor and into the receiving sensor, assuming zero separation. It is clear that this value of $t_{0}$ is determined by the capacitance of the piezoelectric crystals as well as the thickness of, and speed of sound within, the crystals and their impedance matching coatings. The time of flight data recorded by API-V were therefore converted to speed of sound $\mathrm{c}$ using

$$
c=\frac{s}{t-t_{0}}
$$

where $\mathrm{s}$ is the separation of the sensors and $\mathrm{t}$ is the measured time of flight from API-V (on the order of $600 \mu \mathrm{s}$ ).

Experimentation with flight spare sensors also revealed that the envelope of the received signal is more bell shaped than the transmitted signal. This effect, caused by processes such as ringing of each sensor due to its finite Q, means that early peaks in the signal train may not have a large enough amplitude to be detected. Each peak missed in this way causes API-V to overestimate the time of flight by $1 \mu \mathrm{s}$. Before encounter it was expected that, as the probe descended and the density of the atmosphere increased, the received signal would become stronger and fewer peaks 
would be missed in this way. This would manifest itself in the flight data in the form of discontinuities separated by $1 \mu$ s in a plot of time of flight vs. altitude.

Figure 2 shows the recorded API-V dataset taken during Huygens descent. Although API-V was switched on only $600 \mathrm{~s}$ after initial parachute deployment, the upper atmosphere was too tenuous for sufficient atmosphere-sensor coupling and the first successful measurement occurred at an altitude of just above $11 \mathrm{~km}$. It can be seen that speed of sound decreases with altitude, an effect caused mostly by the associated decrease in temperature. There is also a spread of approximately $3 \mathrm{~m} \mathrm{~s}^{-1}$, much larger than the expected absolute accuracy of the sensors of $0.3 \mathrm{~m} \mathrm{~s}^{-1}$ based upon the accuracy of measuring the time of flight and the sensor separation. This spread of data has been studied by taking the difference between the measured time of flight and the value expected for pure nitrogen for all measurements taken below $6 \mathrm{~km}$. Plotting a histogram of the differences does not reveal a simple Gaussian distribution. Instead it shows discrete peaks spaced at $\sim 1 \mu$ s intervals (see figure 3 ). This is compatible with API-V failing to detect a random number of peaks during each measurement instead of simply missing fewer as the pressure increases. The effect is much reduced on the surface with a spread of less than $1 \mathrm{~m} \mathrm{~s}^{-1}$. Turbulent eddies passing between the sensors during descent might have caused a seemingly random change of the scattering properties of the gas, creating this effect. This means that each data point can be considered a lower limit on the speed of sound with a resolution better than 7.5 $\mathrm{cm} \mathrm{s}^{-1}$ based on the $0.25 \mu$ s sampling rate; the absolute speed of sound could be higher by integer multiples of $\sim 30 \mathrm{~cm} \mathrm{~s}^{-1}$, based on the $1 \mathrm{MHz}$ pulse frequency. However, as we show below, it is possible to use information on the sensor and the atmosphere to eliminate this ambiguity and further constrain the results. 


\section{Deducing atmospheric composition from speed-of-sound data}

In a binary mixture, a unique identification of gas components by measuring speed of sound is possible. Hence, in an attempt to extract quantitative information from the data, we have assumed a binary atmosphere for Titan, consisting of nitrogen and methane. This simplification appears to be justified, as the abundance of other components is likely to be limited to trace levels (Niemann et al, 2005). If a third bulk constituent existed on Titan our calculated methane fractions would be slightly under or overestimated, depending on the speed of sound of the pure third constituent. For example, the presence of argon would have an anti-correlated effect on estimated methane abundance, i.e. $1 \%$ molar abundance of argon would result in an underestimation of the methane content by approximately the same amount in this binary model: the increase in speed of sound caused by methane is cancelled by the decrease caused by the presence of argon. This can easily be derived from a first order approximation for the speed of sound (see eq. 2 and, e.g, Hirschfelder et al.,1964), which is mainly a function of mean molecular mass. The molecular mass of methane is $12 \mathrm{~g} / \mathrm{mol}$ lower than nitrogen while that of argon is higher by the same amount. To date, there have been no reported measurements of the speed of sound in mixtures of nitrogen and methane under conditions similar to Titan's, so theoretical models have to be used for the analysis. Unfortunately the lack of experimental data makes any model hard to verify; however, low temperature measurements of the speed of sound in pure nitrogen, as carried out by Younglove and McCarty (1980) or Ewing and Trusler (1992), are useful for this purpose. The Groupe Europeen de Recherches Gazieres' GERG-2004 equation of state (Kunz et al. 2006) is considered to be the most accurate equation of state available at present (Estela-Uribe et al, 2006). A comparison with the available data suggests that the GERG-2004 model should enable 
the methane abundance to be estimated with an accuracy of $0.2 \%$, based on its accuracy in predicting pure nitrogen sound speeds. However, there are no experimental data for nitrogen-methane mixtures under Titan conditions that could be used to verify the accuracy of this - or any other - model. Based on the supplier's information on the other hand, the methane abundances derived from the GERG-2004 model can be expected to be more accurate than $1 \%$. We can demonstrate the difficulty of modelling gas mixtures at Titan conditions: the sound speeds calculated by NIST (1993) yield up to 1\% more methane than the GERG-2004 model, however, we rejected the NIST model because its mixture predictions fail to reproduce the transition between pure nitrogen and low methane ratios. A virial model by Hagermann and Zarnecki (2006) yields up to 3\% more methane than the GERG model, but we suspect the underlying, idealised linear combining rules result in a systematic overestimation of methane. It would therefore be wise to assume that, ultimately, model errors should be no more than $2 \%$. Any such error would have a systematic effect, changing all measurements into the same direction.

The speed of sound is related to the ratio of specific heats $\gamma$ and mean molecular mass $M$ of the gas through

$$
c^{2}=-\gamma \frac{V^{2}}{M}\left(\frac{\partial p}{\partial V}\right)_{T},
$$

where $p$ is pressure, $T$ is temperature and $V$ is the molar volume of the gas.

Note that not only the mean molecular mass but also all the other factors in eq. 2 are functions of the mixing ratio . For details, see Hagermann and Zarnecki (2006) and references therein.

Figure 2 shows a spread in speed of sound of $3 \mathrm{~m} / \mathrm{s}$ and one might quite reasonably argue that an uncertainty of this size is not enough to impose any meaningful 
constraints upon the composition of Titan's atmosphere. There is, however, a data set comprising several thousand measurements and one can significantly reduce the uncertainty by using a Bayesian analysis. This is equivalent to averaging scattered data, the scatter following a probabilistic pattern. We have therefore produced a probability function modelled on the expected properties of the sensor, combined with information gained from laboratory experiments using the flight spare sensors and the observed behaviour of the flight sensor during the descent. For this purpose, it is assumed that the mixture-dependent speed of sound should not vary drastically over small altitude or time intervals (i.e. tens of meters or seconds). With the probability density function covering the applicable model space at all altitudes we then calculate a cumulative probability for the methane content. The solution set is narrowed as the probe descends and more measurements contribute to the cumulative solution. Once a change in methane fraction causes a result incompatible with the cumulative solution, a new solution is sought for the subsequent altitude interval. Thus we avoid falsely imposing artificial altitude resolution on the measurements. Figure 4 illustrates this procedure as a flow chart.

The result is not a definitive solution, but a 'most likely' methane abundance over certain altitude intervals. Provided these intervals cover many compatible measurements, a reliable solution is produced, visible as a sharp probability peak in methane space (or as a thin vertical line, if the altitude interval is large); thus we have effectively traded off the high altitude resolution of many (noisy, but compatible) measurements for a high methane resolution. If there are insufficient measurements to constrain the solution, we obtain a blurred solution space (or several possible solutions). 


\section{Results and discussion}

Assuming that Titan's atmosphere can be approximated by a binary gas mixture and using the pressure and temperature data obtained by Fulchignoni et al's (2005) Huygens Atmospheric Structure Instrument HASI, the most probable methane abundance was derived using the GERG-2004 equation of state. The results are shown in figure 5, where at any particular altitude the results of the analysis are normalised such that black is the most probable solution and white shows regions where the solution approaches a probability of zero. One speed measurement around $2 \mathrm{~km}$ altitude is an outlier, most likely the result of an internal reflection within the sensor and was consequently removed from the dataset. It is possible that a few more measurements could be affected by internal reflections but there is no conclusive evidence for this.

At $11 \mathrm{~km}$ altitude, the results show a methane fraction of $0-2 \%$, with the higher value being confirmed at altitudes below $10.5 \mathrm{~km}$. . Around $8.5 \mathrm{~km}$ this rises to $2-2.5 \%$ methane. There is a general trend of increasing methane abundance towards the surface; the most probable methane abundance in the $0-4.5 \mathrm{~km}$ interval is $3.3 \%$. This trend is not surprising since the saturation point decreases with increasing altitude, as indicated in figure 5.

Even though we can reproduce a decrease of methane abundance with altitude as seen by GCMS (Niemann et al, 2005), our values are somewhat lower than those measured by GCMS. However, one should not forget that the methane to nitrogen ratio derived from either experiment is model-dependent. We propose three possible reasons why our methane values are systematically lower than the GCMS values: 
1) an inaccuracy in the equation of state. In terms of methane abundance the GERG model should be accurate to about $1 \%$, as discussed above. Other model equations of state, however, tend to produce a higher methane fraction;

2) a difference in offset $t_{0}$ between the accurately calibrated flight spare and the flight sensor due to minor manufacturing differences, or;

(3) an unaccounted for systematic offset in the GCMS measurements or model assumptions.

As our results give most probable results rather than absolute values (as an expression of the statistical ambiguity in the finite length of the signal wave train, the dominant source of errors), we will only briefly mention other errors in our measurements. An estimated a speed-of-sound accuracy of $0.3 \mathrm{~m} \mathrm{~s}^{-1}$ based on uncertainties in timing and separation, resulting in a $\sim 1.2 \%$ uncertainty in methane has already been mentioned. Additionally, there is an uncertainty in the sensor separation, caused by thermal contraction, that is on the order of $0.1 \mathrm{~mm}$, which translates into approx. $0.15 \mathrm{~m} \mathrm{~s}^{-1}$, or $0.6 \%$ methane. Note, however, that the resulting error will be systematic, causing an offset of the whole methane composition curve in figure 5, without changing its shape. Furthermore, the finite sampling rate results in a $0.3 \%$ resolution in terms of methane abundance. The finite half-width of a single pulse of $\sim 0.15 \mathrm{~m} \mathrm{~s}^{-1}$ gives an indication of random errors, which results in an additional uncertainty of $0.6 \%$ in methane.

Uncertainties in pressure and temperature measurements will also have an effect. While the impact of the former is negligible, a temperature-related methane abundance error will be less than $1 \%$ per $0.1 \mathrm{~K}$.

We find no evidence for the presence of a cloud layer. Tokano et al. (2006) recently suggested methane drizzle in Titan's atmosphere and pointed out that there should be a cloud of liquid methane at between $\sim 8 \mathrm{~km}$ and $16 \mathrm{~km}$ altitude, but there do not 
appear to be any anomalies in speed-of-sound data above $8 \mathrm{~km}$. This does not however preclude the presence of such a cloud later.

We cannot give a minimum methane abundance above $10.5 \mathrm{~km}$ because there are insufficient data points to identify a unique solution, as indicated by a blurred grey region (not too much attention should be paid to the shade of gray as an indicator of absolute probability).

Within this analysis, we cannot make any statements with regard to a time-dependent variation of methane on the surface. Additionally, the physical configuration of the sensors after landing, and the separation of temperature from speed of sound instruments precludes any statements with regard to a time-dependent variation of methane on the surface. In this context, it is important to note that while this instrument as built would have given an interesting history of temperature fluctuations in the atmosphere post-impact (where the descent speed, and thus the associated turbulence, was zero), its position on the underside of the probe precluded such measurements in the hope of measuring the composition of surface liquids.

\section{Implications for Future Missions}

Although the instrument functioned more-or-less as designed, the scatter in the results makes it difficult to derive robust constraints on composition variations with altitude. A factor may be the influence of turbulence - although instruments of this sort have been flown on balloon platforms, they have not been operated on vehicles with a significant $(>1 \%$ of sound speed) velocity relative to the atmosphere. Thus the results presented here should not be taken as representative of the speed-of-sound technique as a whole. Future Titan missions might involve balloons - were the Huygens SSP API-V flown on such a semi-static platform in the lower atmosphere, it would yield data with significantly less scatter. 


\section{Conclusions}

API-V was the first instrument to measure speed of sound outside the terrestrial system, which has resulted in constraints on the methane abundance in Titan's lower atmosphere. A Bayesian approach has been applied to reduce ambiguities in the dataset, generating a most likely methane abundance at altitudes for which successful measurements were available. Analysis here has indicated that at $10 \mathrm{~km}$ altitude the methane fraction on Titan was $1.5-2 \%$. It increases with decreasing altitude to $3.3 \%$ at $4.6 \mathrm{~km}$. Below $4.6 \mathrm{~km}$ altitude the mole fraction of methane probably remains at $3.3 \%$. In this work, we used the most recent reference equation of state available, but results are model-dependent. Experimental study of relevant gas mixtures under Titan conditions would enable us to verify model accuracy and thus further constrain methane abundance.

\section{Acknowledgments}

This work has been funded by the UK Particle Physics and Astronomy Research Council. R.D.L. is supported by NASA via the JPL Cassini project. We are also very grateful to Paul Withers and an anonymous reviewer, whose helpful comments greatly improved this paper.

\section{References}

Estela-Uribe, J.F., J.P.M. Trusler, C.R. Chamorro, J.J. Segovia, M.C. Martin and M.A. Villamañán, 2006: Speeds of sound in $\left\{(1-\mathrm{x}) \mathrm{CH}_{4}+\mathrm{xN}_{2}\right\}$ with $\mathrm{x}=(0,10001,0.19999$, and 0.5422 ) at temperatures between $170 \mathrm{~K}$ and $400 \mathrm{~K}$ and pressures up to $30 \mathrm{MPa}$. J. Chem Thermodynamics 38, 929-937. 
Ewing, M.B. and J. P. M. Trusler, 1992: Second acoustic virial coefficients of N2. Physica A 184, 415-436.

Fulchignoni, M., and 42 colleagues, 2005. In situ measurements of the physical characteristics of Titan's environment. Nature 438(7069), 785-791.

Hagermann, A. and J.C. Zarnecki, 2006: Virial treatment of the speed of sound in cold, dense atmospheres and application to Titan. Mon. Not. Roy. Astron. Soc. 368, 321324.

Hirschfelder J. O., C.F. Curtiss and R.B. Bird, 1964: Molecular Theory of Gases and Liquids, corrected edn., John Wiley \& Sons, New York

Kunz, O., Klimeck, R., Wagner, W. and Jaeschke, M, 2006: The GERG-2004 WideRange Reference Equation of State for Natural Gases and Other Mixtures. To be published as GERG Technical Monograph. Fortschr.-Ber. VDI, VDI-Verlag, Düsseldorf.

Niemann, H.B., S.K. Atreya, S.J. Bauer, G.R. Carignan, J.E. Demick, R.L. Frost, D. Gautier, J.A. Haberman, D.N. Harpold, D.M. Hunten, G. Israel, J.I. Lunine, W.T. Kasprzak, T.C. Owen, M. Paulkovich, F. Raulin, E. Raaen, S.H. Way, 2005: The abundances of constituents of Titan's atmosphere from the GCMS instrument on the Huygens probe. Nature 438(7069), 779-784. 
NIST, 1993: NIST Standard Reference Database 14, National Institute of Standards and Technology, Gaithersburg, MD.

Tokano, T., C.P McKay, F.M. Neubauer, S.K. Atreya, F. Ferri, M. Fulchignoni \& H.B. Niemann, 2006: Methane drizzle on Titan. Nature 442(7101), 432-435.

Younglove, B. A. and R. D. McCarty, 1980: Speed-of-sound measurements for nitrogen gas at temperatures from 80 to $350 \mathrm{~K}$ and pressures to $1.5 \mathrm{MPa}$. J. Chem. Thermodyn. 12, 1121-1128

Zarnecki, J.C., M. Banaszkiewicz, M. Bannister, W. V. Boynton, P. Challenor, B. Clark, P.M. Daniell, J. Delderfield, M.A. English, J.R.C. Garry, J.E. Geake, S.F. Green, B. Hathi, S. Jaroslawski, M.R. Leese, R.D. Lorenz, J.A.M. McDonnell, N. Merryweather-Clarke, C.S. Mill, R.J. Miller, G. Newton, D.J. Parker, H. Svedhem and M.J. Wright, 1997: The Huygens Surface Science Package. ESA SP-1177, Huygens: Science, Payload and Mission (ed. Wilson, A.), 177-195 (ESA Publications Division, Noordwijk, The Netherlands.

Zarnecki, J. C., M. R. Leese, J.R.C. Garry, N. Ghafoor, B Hathi, 2002: Huygens' Surface Science Package. Space Sci. Rev. 104(1) 593-611.

Zarnecki, J.C., M.R. Leese, B. Hathi, A.J. Ball, A. Hagermann, M.C. Towner, R.D. Lorenz, J.A.M. McDonnell, S. F. Green, M.R. Patel, T.J. Ringrose, P. D. Rosenberg, K.R. Atkinson, M.D. Paton, M. Banaszkiewicz, B.C. Clark, F. Ferri, M. Fulchignoni, N.A.L. Ghafoor, G. Kargl, H. Svedhem, J. Delderfield, M. Grande, D.J. Parker, P.G. 
Challenor and J.E. Geake, 2005: A soft solid surface on Titan at the Huygens landing site as measured by the Surface Science Package (SSP). Nature 438 (7069) 792-795. 


\section{Figure captions}

Figure 1: Schematic of the location of the SSP instrument and the API-V sensors on board the Huygens spacecraft. The API-V sensors are on the rim of the SSP top hat structure, facing each other. The top hat is covered with a grid-like electromagnetic shield.

Figure 2: Speed of sound as measured by API-V versus altitude and speed of sound for various mixtures of nitrogen and methane according to the GERG-2004 equation of state.

Figure 3: Histogram of the number counts (for clarity: square root of count number), for a difference in measured time of flight between the two sensors after landing. Because of the low noise level, the discrete offset of $1 \mu$ s multiples becomes particularly obvious in the post-landing measurements.

Figure 4: Flow chart of the Bayesian analysis procedure. The distribution of possible methane compositions after speed-of-sound measurement $\mathrm{n}(1)$ is compared with the distribution of compositions derived from measurement $n+1$ (2) using the probability distribution function of the sensor's response (3) and the a priori assumption of the methane fraction being constant over short altitude scales (4). If the results are compatible, this results in a more accurate estimate of Methane fraction (5). If the two values are incompatible, the methane fraction up to measurement $\mathrm{n}$ is accepted as best estimate and a new solution is found for the subsequent altitude interval. 
Figure 5: Most probable distribution of methane abundance vs. altitude (vertical bars) after Bayesian analysis, with an effective resolution of $0.3 \%$. The dotted line shows the saturation abundance of methane as given by the NIST mixture property database (1993), 'X's mark the methane abundance as reported by GCMS (Niemann et al, 2005). Methane abundance decreases with altitude. The offset between our (model dependent) solution and the GCMS measurements is approximately constant. At high altitude, the methane abundance is ambiguous because of a lack of comparable measurements. 
Figure 1 - Hagermann et al.: Speed of sound

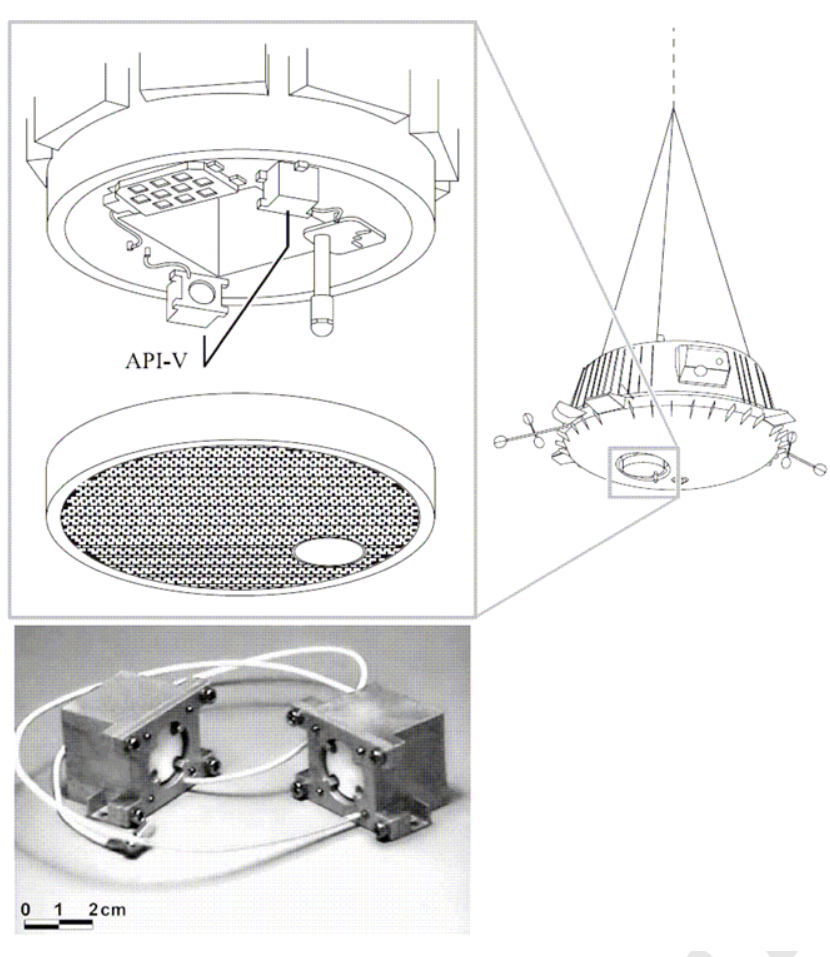


Figure 2 - Hagermann et al.: Speed of sound

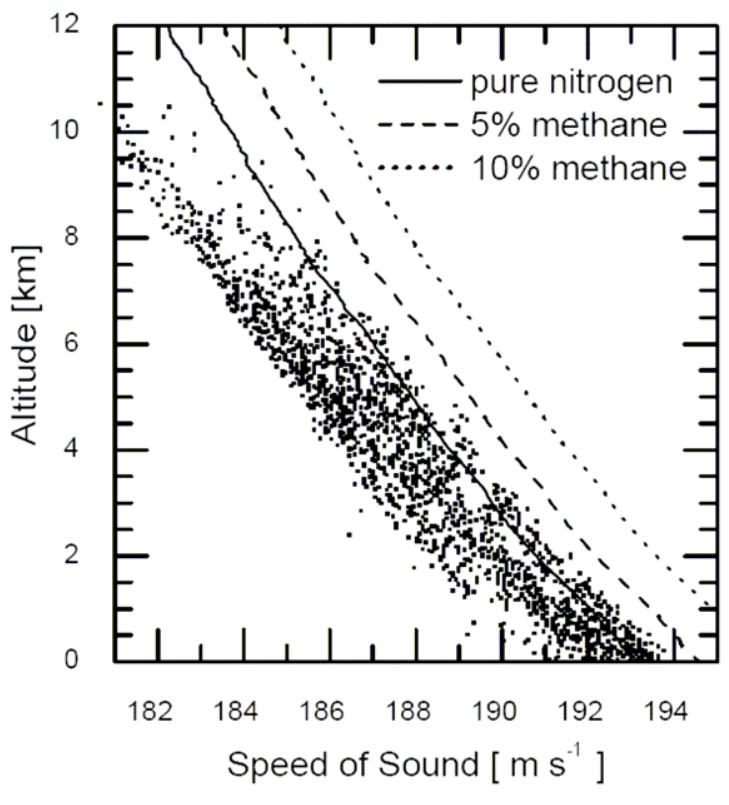


Figure 3 - Hagermann et al.: Speed of sound

API-V post-landing measurements

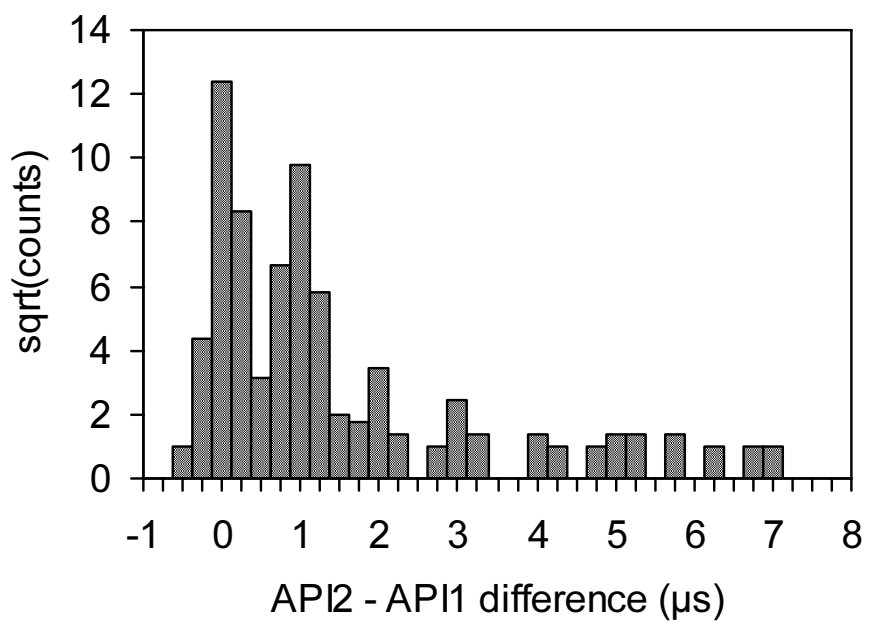


Figure 4 - Hagermann et al.: Speed of sound

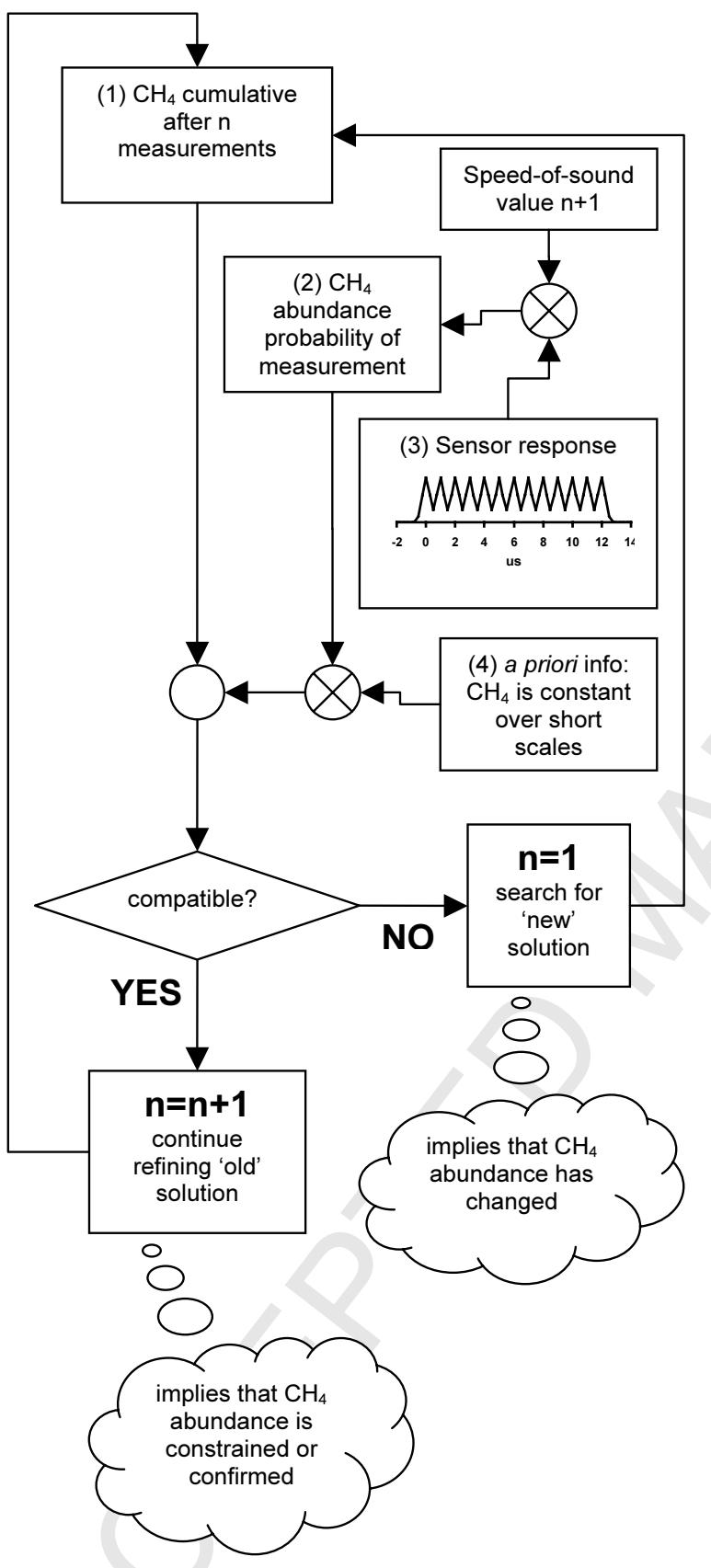


Figure 5 - Hagermann et al.: Speed of sound

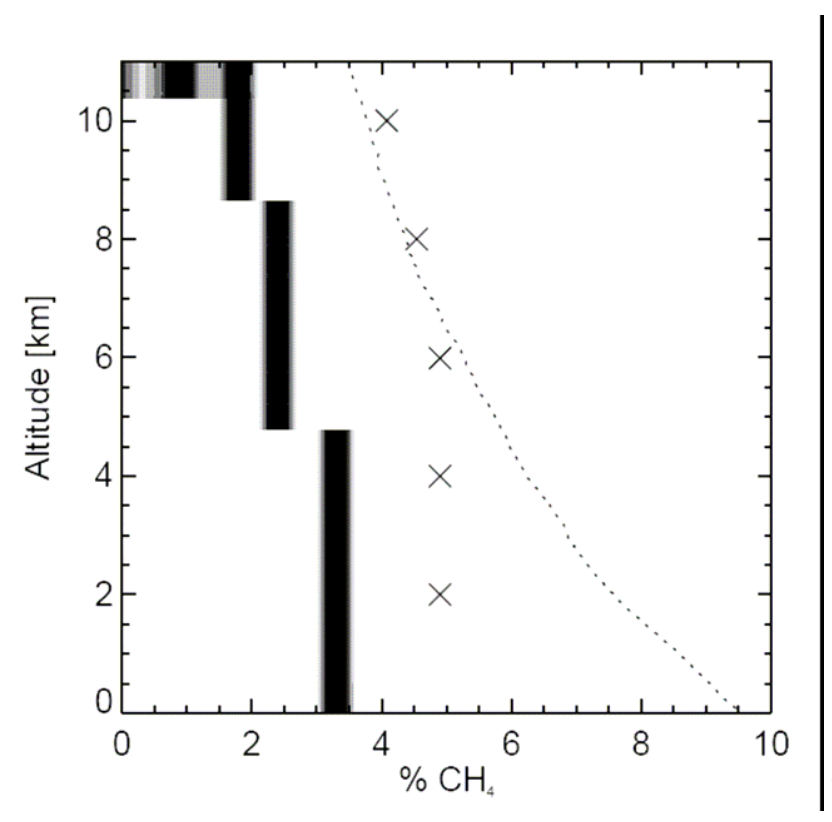

